\title{
Oxidation features of plastic deformed Zr-based bulk metallic glass
}

\author{
Zheng Hu, Lei Li, Yanping Hu, Jianshuo Xing, Bingchen Wei* \\ Key Laboratory of Microgravity (National Microgravity Laboratory), Institute of Mechanics, Chinese Academy of Sciences, Beijing 100190, PR China
}

\section{A R T I C L E I N F O}

\section{Article history:}

Received 25 July 2010

Received in revised form 19 January 2011

Accepted 13 February 2011

Available online 21 February 2011

\section{Keywords:}

Bulk metallic glass

Indentation

Oxidation

Shear band

\begin{abstract}
A B S T R A C T
The surface morphology of in situ deformed, pre-deformed, undeformed and crystallized $\mathrm{Zr}_{47.9} \mathrm{Ti}_{0.3} \mathrm{Ni}_{3.1} \mathrm{Cu}_{39.3} \mathrm{Al}_{9.4}$ bulk metallic glass in air at elevated temperatures are investigated to improve the understanding of the effect of plastic deformation on the oxidation. The plastic deformation is performed through instrumental macroindentation, while could provide a well developed shear offset pattern around the indents at lower temperatures. The oxidation experimental results show that the in situ formed and pre-existed shear bands are more susceptible to oxidation. The plastic deformation region during homogenous deformation has also a significant oxidation sensitivity compared with undeformed material. To clarify the oxidation mechanism of shear band, specimens with surface scratches were also studied. The mechanism for the preferential oxidation of shear bands and of the plastic deformation region is discussed.
\end{abstract}

(C) 2011 Elsevier B.V. All rights reserved.

\section{Introduction}

In order to use the metallic glasses (MGs) at elevated temperatures for industrial applications, an understanding of its oxidation behavior under oxygen-containing atmospheres is essential, especially when the surface-to-bulk ratio of the parts is high. Although many works have been done for studying the oxidation behaviors of MGs, mechanisms of oxidation are still not very clear [1-10]. For example, metallic glasses (or amorphous alloys) are in general believed to be more oxidation and corrosion resistant in comparison to their crystalline counterparts, due to the lack of any crystal-like microstructure, such as grain boundaries, which would otherwise act as local active sites for corrosion and oxidation $[2,3]$. On the other hand, there is also a large amount of metallic glass systems which show poorer oxidation resistance with respect to their crystalline counterparts [4-8]. The easier oxidation can be explained in terms of the presence of extra free volume in MGs, which provides an easy, short circuit path for the inward diffusion of oxygen. These controversial results indicate that extensive investigations on the underlying oxidation mechanism in MGs are needed. Besides, little work has been done on the effect of plastic deformation on the oxidation behavior of MGs. Plastic deformation in metallic glass is localized in shear bands at low temperature and high strain rate, while tends to be a viscous flow at elevated temperatures and low rates. A distinct change of structure in MGs is expected during plastic deformation, which will in turn influence the oxidation characteristics of MGs. In this

\footnotetext{
* Corresponding author. Tel.: +86 10 82544118; fax: +86 1082544096 .

E-mail address: weibc@imech.ac.cn (B.Wei).
}

work, the oxidation features of a Zr-based bulk metallic glass undergone in situ and ex situ deformation from room temperature to $500^{\circ} \mathrm{C}$ are investigated. This may provide valuable information on high temperature processing (such as micro-molding and nano-imprinting). The oxidation features of shear bands may also be helpful to understand the structural characteristics of shear bands.

\section{Experimental procedures}

The $\mathrm{Zr}_{47.9} \mathrm{Ti}_{0.3} \mathrm{Ni}_{3.1} \mathrm{Cu}_{39.3} \mathrm{Al}_{9.4}$ ingot was prepared by arc melting the mixtures of pure metals under an argon atmosphere and the alloy was re-melted several times to ensure chemical homogeneity. Cylinders of the alloys were prepared in the shape of $5 \mathrm{~mm}$ in diameter by suction casting under pure argon atmosphere. Specimens $3 \mathrm{~mm}$ in length were cut from these rods. The amorphous structure of the samples was confirmed by X-ray diffraction (XRD) using $\mathrm{Cu} K \alpha$ radiation. Thermal analysis was performed with a Netzsch DSC 404C differential scanning calorimeter under argon atmosphere, at a constant heating rate of $20^{\circ} \mathrm{C} / \mathrm{min}$.

Oxidation during elevated temperature deformation was fulfilled by using instrumental macroindentation method in air environment at temperatures from 150 to $500^{\circ} \mathrm{C}$ for the duration of $10 \mathrm{~min}$. Then the macroindentation tests were performed in displacement-control mode with a conical diamond tip to the maximum depth about $250 \mu \mathrm{m}$ at the displacement rate of $0.4 \mathrm{~mm} / \mathrm{min}$. After the indentation tests, the samples were natural cooled in the furnace. Some specimens were predeformed (through depth-sensing macroindentation to the maximum depth about $250 \mu \mathrm{m}$ ) at room temperature to introduce shear bands in the samples. Some of the pre-deformed samples were annealed in vacuum at temperature well above the crystallization temperature of the alloy to reach a fully crystalline state. These pre-deformed and crystallized specimens were exposed to air at elevated temperature with the same thermal procedures as that of the elevated temperature deformation.

Surfaces of samples were polished with standard metallographic techniques to a mirror finish for macroindentation tests. Others were ground to different surface roughness through grit SiC sandpaper $(2.5 \mu \mathrm{m}, 10 \mu \mathrm{m}, 80 \mu \mathrm{m}$, respectively) to introduce scratches on the sample surface. The morphology of the oxidation surfaces was observed by a JSM-6460 scanning electron microscope (SEM). 

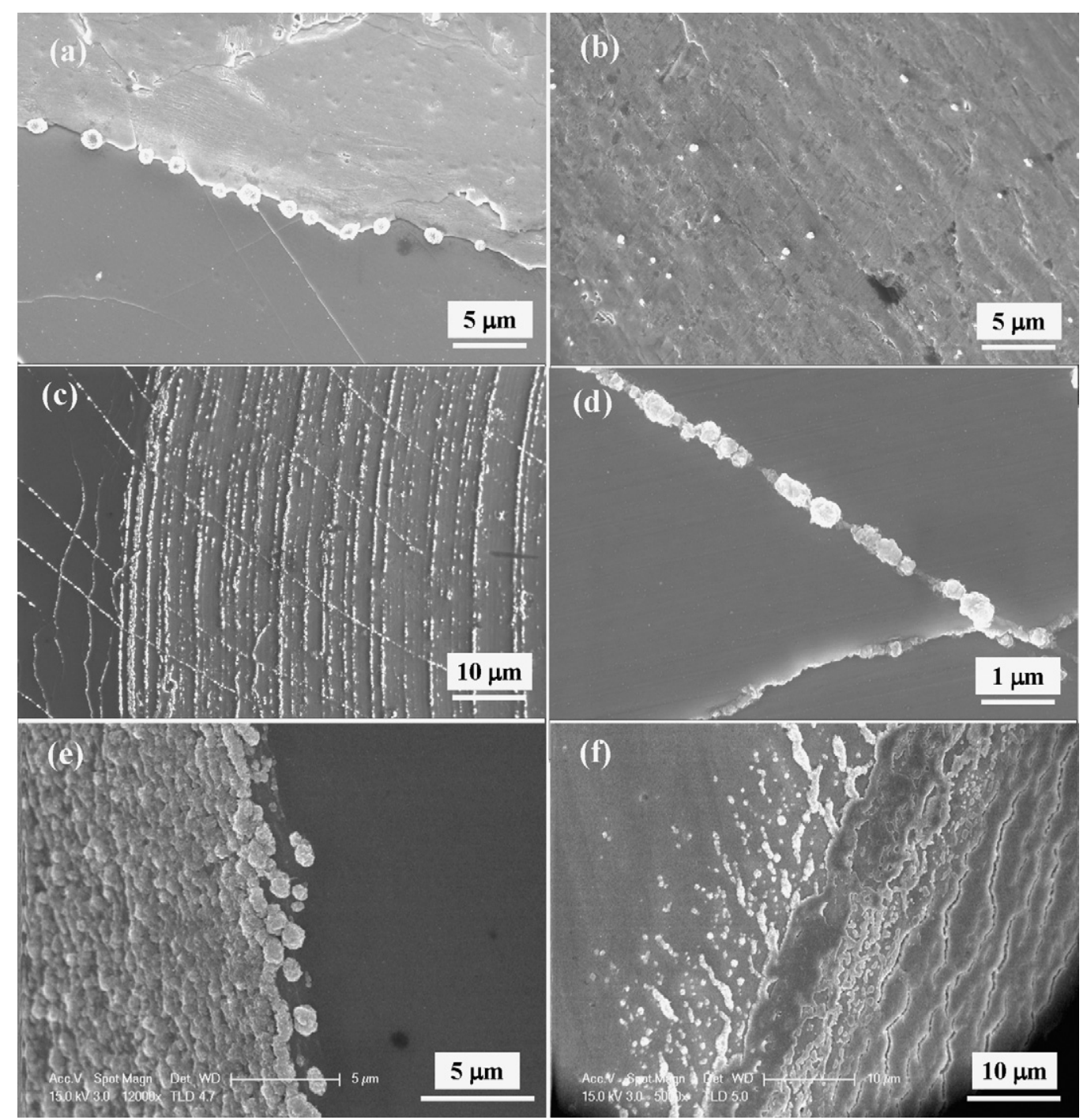

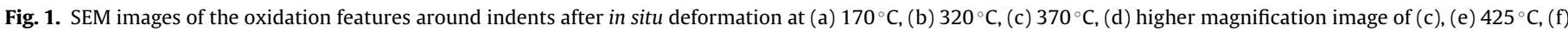
$450^{\circ} \mathrm{C}$.

\section{Results and discussion}

The amorphous structure of the as-cast $\mathrm{Zr}_{47.9} \mathrm{Ti}_{0.3} \mathrm{Ni}_{3.1} \mathrm{Cu}_{39.3} \mathrm{Al}_{9.4}$ BMG was confirmed by XRD. Glass transition temperature $\left(T_{\mathrm{g}}\right)$, crystallization temperature $\left(T_{\mathrm{X}}\right)$ and the supercooled liquid region $\left(\left(T_{\mathrm{X}}=T_{\mathrm{X}}-T_{\mathrm{g}}\right)\right.$ of the BMG are characterized to be 429,489 and $60^{\circ} \mathrm{C}$, respectively, by DSC measurements at the heating rate of $20^{\circ} \mathrm{C} / \mathrm{min}$.

In situ indentation tests at elevated temperatures were performed in an open furnace. Typical surface morphologies of indents after in situ indentation tests at the different temperatures are shown in Fig. 1. Shear offset patterns around the indents consisting of radial and concentric shear offsets does not change greatly from room temperature to $370^{\circ} \mathrm{C}$. Island-like oxide particles are observed to form on the edge of the indents (Fig. 1a) at $170^{\circ} \mathrm{C}$. A few oxide particles can be found on the inner surface of the indents at $320^{\circ} \mathrm{C}$ (Fig. 1b). It is interesting to find that most shear offsets inside and outside the indents are decorated by oxide particles at $370{ }^{\circ} \mathrm{C}$ (Fig. 1c and d), whereas few oxide particles form on the surrounding material. This clearly demonstrates the preferential oxidation of the in situ formed shear offsets than the amorphous matrix. With further increase in temperature, these oxide particles increase gradually in size, and form worm-like hillocks along the shear offsets. At $425^{\circ} \mathrm{C}$, there is no shear offsets spreading outside the indent, and oxide hillocks distribute homogeneously on the inner surface of the indents (Fig. 1e). The undeformed area tends to form a few oxide particles at $450^{\circ} \mathrm{C}$, and cracks on the oxide layer can be found (Fig. 1f).

The above results indicate that the in situ deformation at high temperatures leads to the preferential oxidation at shear offsets at relative low temperature and at the viscous deformation area at higher temperature. For further understanding the effect of shear bands on the oxidation behavior of the BMG, the oxidation surface morphology of the specimen with pre-existed shear bands are also studied. The shear bands were introduced at room temperature, and oxidation experiments were carried out at high temperatures in air. It can be found that no preferential oxidation on shear bands can be found below $390^{\circ} \mathrm{C}$ (Fig. 2a). Precipitation of oxides on shear offsets can be found at $450^{\circ} \mathrm{C}$, wherein oxidation of matrix also takes place (Fig. 2b). At $510^{\circ} \mathrm{C}$, oxidation particles spread throughout the surface, wherein wormlike hillocks form following the pre-existed shear offset traces, and oxide-islands form on other sites as shown in Fig. 2c and d.

It can be seen from the oxidation features of the pre-deformed specimens that oxidation still prefers to form on the pre-existed 


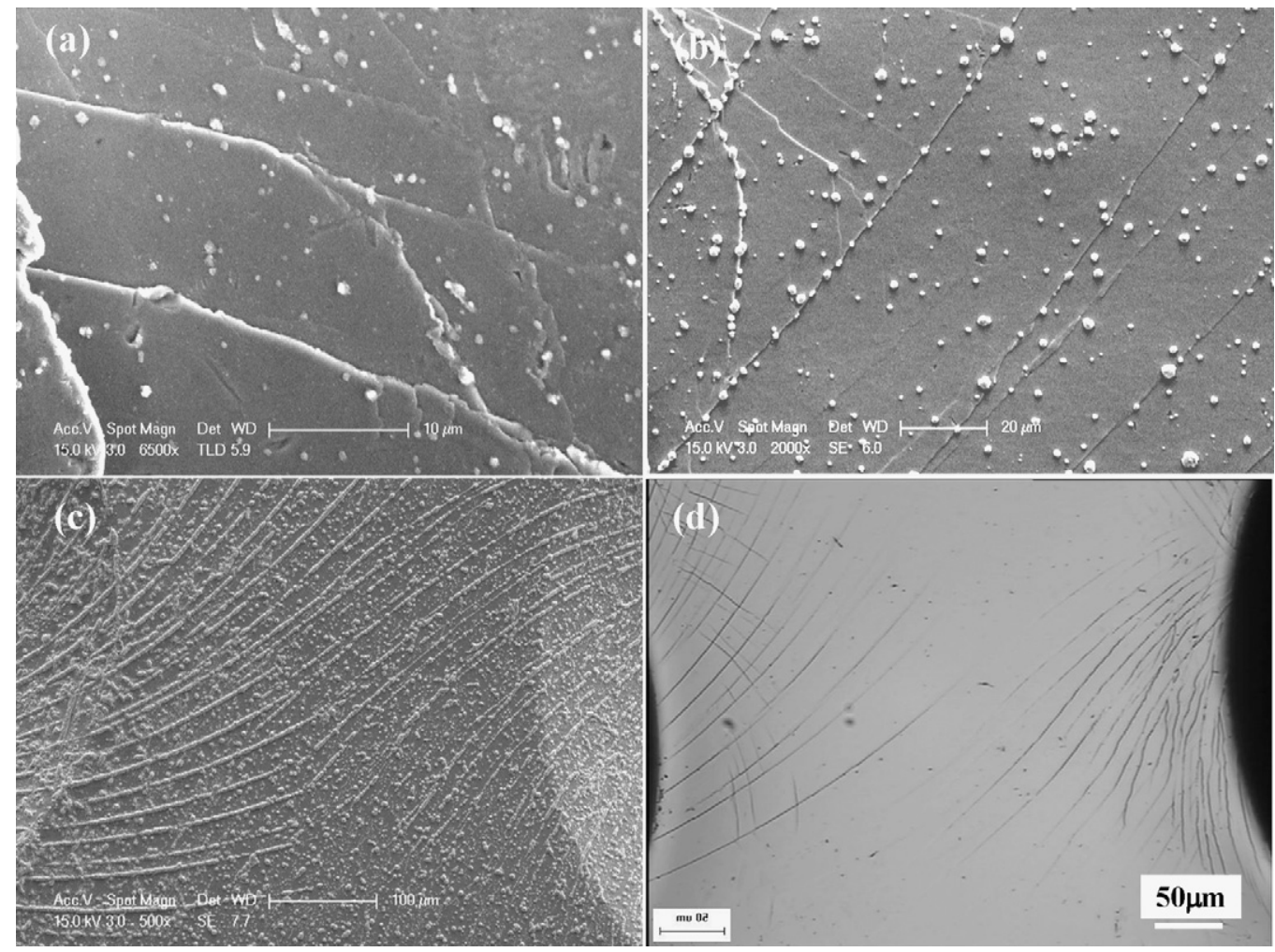

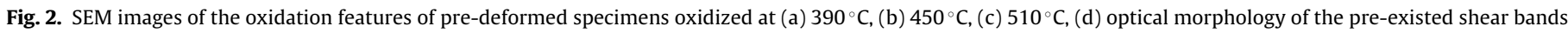
pattern before oxidation experiments corresponding to (c).

shear bands, but takes place at higher temperatures compared with that on the in situ formed shear bands. The oxidation products are consisted mainly of tetragonal $\mathrm{ZrO}_{2}\left(\mathrm{t}-\mathrm{ZrO}_{2}\right)$ after oxidation at 390 and $450^{\circ} \mathrm{C}$, while a minor amount of $\mathrm{Cu}$ phase was also detected at $450^{\circ} \mathrm{C}$ (Fig. 3a). In situ deformed and pre-deformed samples form the same oxidation products. It should be noted that the shear bands observed around the indents are in fact the shear offsets along the shear plane. The surface imperfections could provide easier nucleation sites for oxidation [11,12]. Therefore, the preferential oxidation on the shear bands may be attributed to structural change in shear band, and the surface offsets as well. To clarify this, oxidation features of the specimens with scratches at different scales are also studied. The scratches were introduced by grinding the as- cast specimens using SiC sandpaper with different grits. The surface morphologies of the specimens after oxidation experiments are shown in Fig. 4. At $390^{\circ} \mathrm{C}$, no oxides can be found on the scratches and smooth areas (Fig. 4a), and at $450^{\circ} \mathrm{C}$, oxide-islands disperse on the surface (Fig. $4 \mathrm{~b}$ ). The temperature at which oxides begin to form is roughly consistent with that of the undeformed part of in situ deformed specimens. However, no clear preferential oxidation can be found on the scratches here, although some of scratches are quite sharp.

The oxidation features of the crystalline alloy were also investigated for comparison. The specimens were pre-deformed at room temperature, and annealed in vacuum to reach a fully crystalline state. After crystallization the shear bands become less clear and
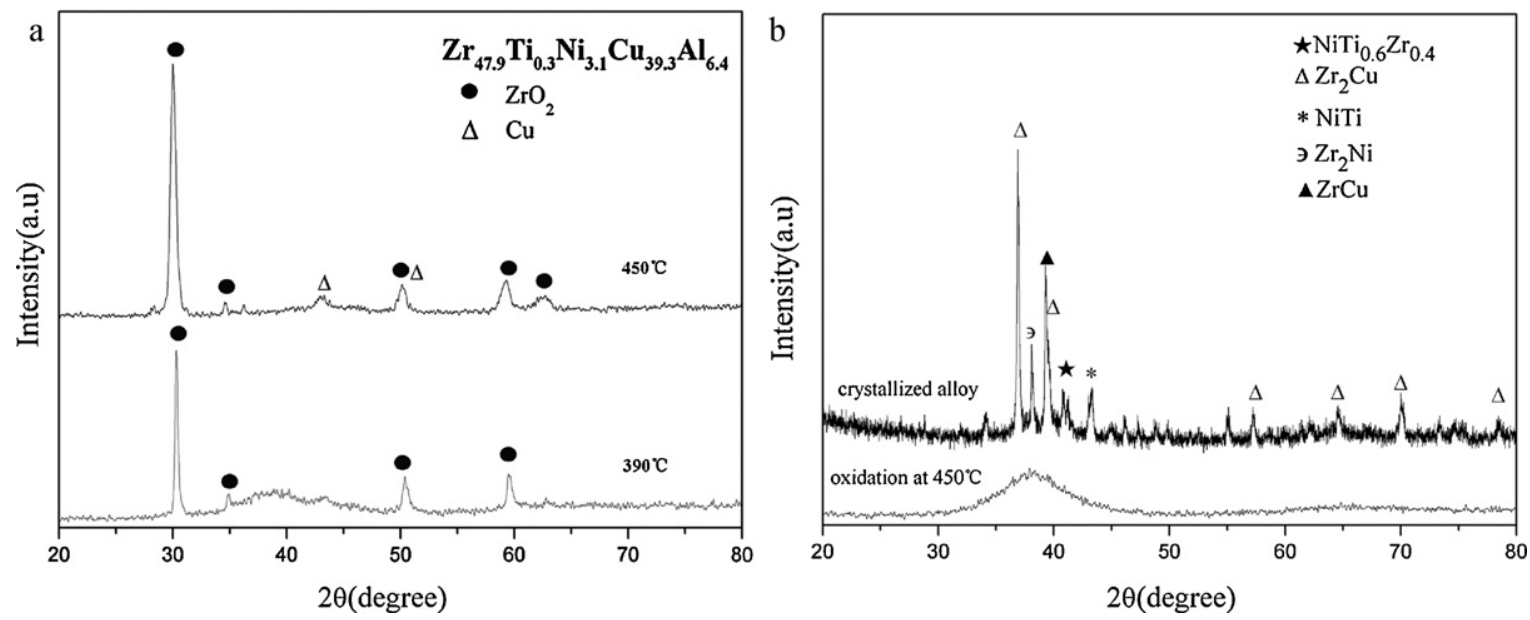

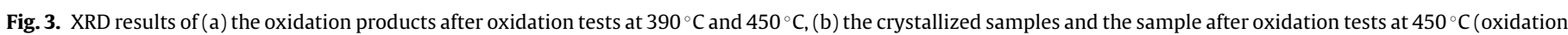
layer removed). 

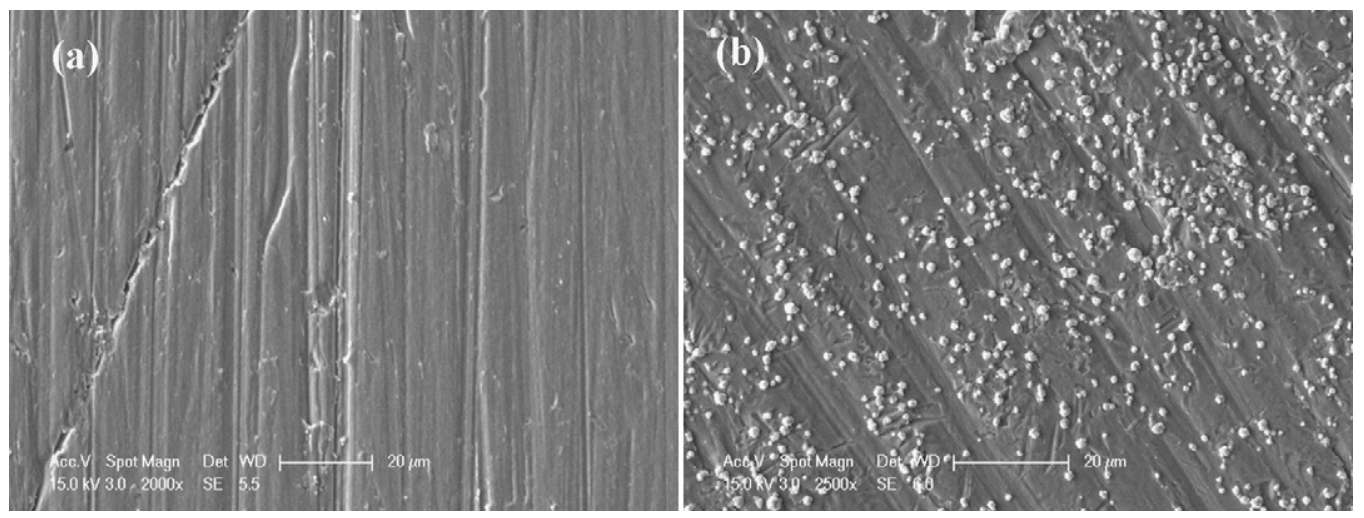

Fig. 4. Oxidation morphology of as-cast specimen with different surface roughness oxidized at (a) $10 \mu \mathrm{m}$ grid at $390{ }^{\circ} \mathrm{C}$, (b) $80 \mu \mathrm{m}$ grid at $450{ }^{\circ} \mathrm{C}$.

decrease in number (Fig. 5). No oxides can be found neither on shear bands nor on smooth surface up to $450^{\circ} \mathrm{C}$.

From the oxidation features of the amorphous alloys (in situ deformed, pre-deformed, and as-cast states) and the crystalline counterpart alloy, it can be found that the undeformed specimens or the undeformed parts of the deformed specimen begin to form surface oxides at about $450^{\circ} \mathrm{C}$, wherein the crystalline alloy does not form any oxides at $450^{\circ} \mathrm{C}$. This indicates that the crystalline alloy is more oxidation resistant compared with amorphous alloys. This agrees with the results of other Zr-based BMGs [4-8]. The amorphous samples remain the amorphous state after the oxidation experiments below $450^{\circ} \mathrm{C}$ as shown in Fig. 3b. The crystalline phases in the crystallized sample are also shown in Fig. 3b. Furthermore, in this work the oxidation features of the in situ and pre-deformed specimens show a clearly preferential oxidation of the shear bands, although the two states vary in the beginning temperature of oxidation. It has already been reported that shear bands subjected to chemical attack etch more readily than the surrounding undeformed material $[13,14]$. This effect could be explained in terms of disruption of the atomic short-range order inside the shear bands [15]. However, it is also possible that the effect is caused by the residual stresses around the shear bands [16]. Here, the oxidation experiments are carried out at elevated temperatures, even higher than the glass transition temperature. The residual stress induced by the inhomogeneous deformation could be relaxed by the viscous flow and the relaxation of the amorphous structure. In addition, the non-preferential oxidation on scratches also supports that the easier oxidation of shear bands is related to the structural or local temperature change in shear band, rather than residual stress or surface imperfections. The precise determining of the structure in shear bands is still a significant challenge. Increase in free volume, nanocrystallization and formation of nano voids in shear bands are all possible [15,17]. Significant nanocrystallization may not occur here, as nanocrystallization is often found to be more oxidation resistant than the amorphous state in $\mathrm{Zr}$-based metallic glasses [4-8]. The slower oxidation for the crystalline specimens here also supports this point. The local increase in free volume and significant shear-induced dilatation of the local structure are proposed to be the reason for the easier diffusion of oxygen inward the sample. On the other hand, it is known that the propagation of shear bands leads to a local increase of the temperature [15,17] Although the degree of the temperature rise is still under debate, the in situ formed low viscosity layer with higher temperature could explain the preferential oxidation of shear bands at low temperature as shown in Fig. 1. It is known that shear bands have a thickness of about 10-20 nm [18], whereas the observed oxidation features here are rather in the micron scale. This may suggest that the premature and preferential oxidation in the shear offsets during in situ deformation at lower temperatures is mainly caused by the local temperature rise during the rapid propagation of shear bands. When the in situ deformation is carried out in the homogeneous deformation regime (above $\sim 400^{\circ} \mathrm{C}$ for the present case), the homogeneous flow of the BMG also introduces additional free volume in plastic deformation region $[15,19]$, which still leads to an accelerated oxidation of indents compared with the undeformed material.

In contrast, for the pre-deformed specimens, the pre-existed shear bands undergo relaxation during the heating process of oxidation experiments, which annihilates the extra free volume in shear bands. Furthermore, there is no temperature rise induced by the propagation of shear bands for the pre-deformed specimens during the oxidation experiments. This is the reason for the increase of the temperature for oxides formation and the less significant preferential oxidation of shear bands in the pre-deformed speci-
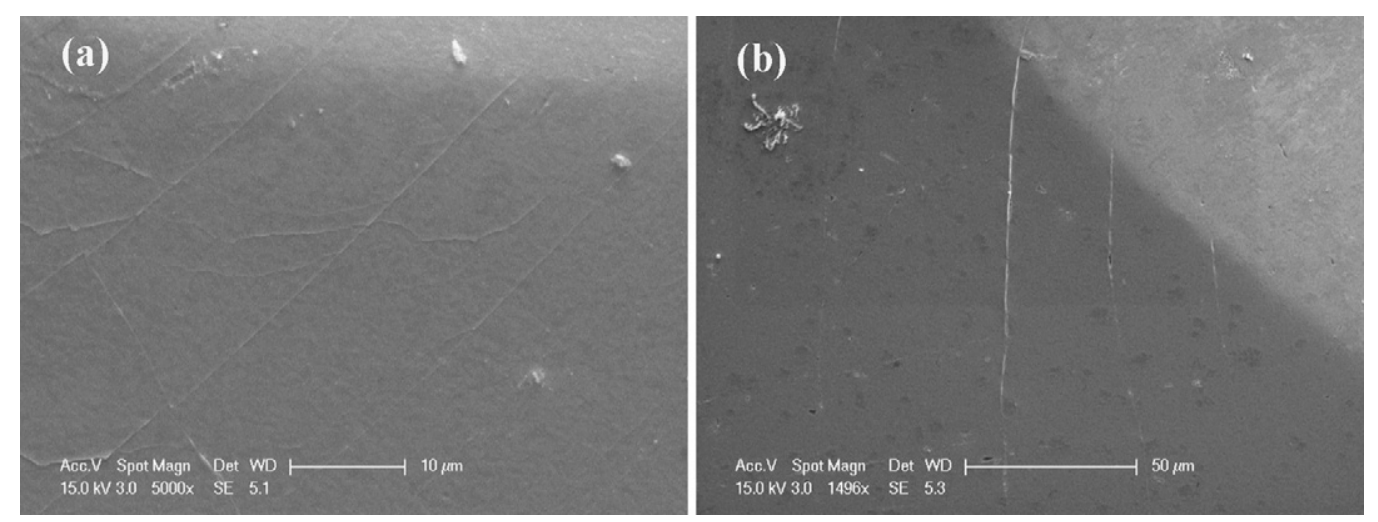

Fig. 5. Surface morphology of the crystallized specimens oxidized at (a) $390^{\circ} \mathrm{C}$, (b) $450^{\circ} \mathrm{C}$. 
mens. It is worth noting that the relaxation cannot fully recover the structural disruption in shear band, even when the oxidation temperature is higher than glass transition temperature, as the preferential oxidation on shear bands still can be found at $450{ }^{\circ} \mathrm{C}$ (Fig. 2b). At $510^{\circ} \mathrm{C}$, which is higher than the crystallization temperature of the alloy, easier oxidation on shear bands still can be seen (Fig. 2c). This suggests that the pre-existed shear bands still leave some defects which cannot be recovered through relaxation, glass transition and crystallization.

\section{Conclusions}

The effect of plastic deformation on the oxidation morphology of $\mathrm{Zr}_{47.9} \mathrm{Ti}_{0.3} \mathrm{Ni}_{3.1} \mathrm{Cu}_{39.3} \mathrm{Al}_{9.4} \mathrm{BMG}$ was studied through controlling the deformation method. The results show that the in situ deformation in air leads to a premature oxidation. Within inhomogeneous deformation regime, the shear bands exhibit an obviously preferential oxidation than surrounding materials, while within homogeneous deformation regime deformation region also have much less oxidation resistance than the undeformed region. The pre-existed shear bands introduced by room temperature deformation are also easier to oxidation. The preferential oxidation of shear bands is related to the local temperature rise around the shear bands during their propagation, as well as the increase of free volume and unrecoverable defects in shear bands. The latter cannot be fully recovered through relaxation, glass transition and crystallization. Furthermore, the BMG is more easily to subject to oxidation than its crystalline counterpart.

\section{Acknowledgments}

This work is financially supported by the National Nature Science Foundation of China (Grant Nos. 50731008, 51071166 and 50771102) and National Basic Research Program of China (973 Program, No. 2007CB613905).

\section{References}

[1] U. Köster, L. Jastrow, Mater. Sci. Eng. A 449-451 (2007) 57-62.

[2] G. Wei, B. Cantor, Acta Metall. 36 (1988) 2293-2305.

[3] D.L. Cocke, G. Liang, M. Owens, D.E. Halverson, D.G. Naugle, Mater. Sci. Eng. 99 (1988) 497-500.

[4] W. Kai, Y.R. Chen, T.H. Ho, H.H. Hsieh, D.C. Qiao, F. Jiang, G. Fan, P.K. Liaw, J. Alloys Compd. 483 (2009) 519-525.

[5] C.Y. Tam, C.H. Shek, J. Mater. Res. 20 (2005) 1396-1403.

[6] W. Kai, H.H. Hsieh, T.G. Nieh, Y. Kawamura, Intermetallics 10(2002)1265-1270.

[7] Y. Wu, T. Nagase, Y. Umakoshi, J. Non-Cryst. Solids 352 (2006) 3015-3026

[8] C.W. Kim, H.G. Jeon, D.B. Lee, Mater. Lett. 62 (2008) 584-586.

[9] J. Kim, K. Kang, S. Yoon, S. Kumar, H. Na, C. Lee, Acta Mater. 58 (2010) 952-962.

[10] X. Sun, S. Schneider, U. Geyer, W.L. Johnson, M.-A. Nicolet, J. Mater. Res. 11 (1996) 2738-2743.

[11] U. Wolff, A. Gebert, J. Eckert, L. Schultz, J. Alloys Compd. 346 (2002) 222-229.

[12] G. Steinbrink, B. Punge-Witteler, U. Köster, Mater. Sci. Eng. A 133 (1991) 624-629.

[13] C.A. Pampillo, Scr. Metall. 6 (1972) 915-917.

[14] P.T. Vianco, J.C.M. Li, J. Mater. Sci. 22 (1987) 3129-3138

[15] C.A. Schuh, T.C. Hufnagel, U. Ramamurty, Acta Mater. 55 (2007) 4067-4109.

[16] V. Lakshmanan, J.C.M. Li, C.L. Tsai, Acta Metall. Mater. 38 (1990) 625-629.

[17] J.J. Lewandowski, A.L. Greer, Nat. Mater. 5 (2006) 15-18.

[18] Y. Zhang, A.L. Greer, Appl. Phys. Lett. 89 (2006) 071907.

[19] P.D. Hey, J. Sietsma, A.V.D. Beukel, Acta Mater. 46 (1998) 5873-5882. 